\title{
Staffing Patterns of Primary Care Practices in the Comprehensive Primary Care Initiative
}

\author{
Deborab N. Peikes, PbD, MPA ${ }^{1}$ \\ Robert J. Reid, $M D, P b D^{2}$ \\ Timotby J. Day, MSPH \\ Derekb D. F. Cornwell, $P b D^{1}$ \\ Stacy B. Dale, MPA ${ }^{1}$ \\ Richard J. Baron, MD, MACP4 \\ Randall S. Brown, $P b D^{1}$ \\ Rachel J. Shapiro, MPP' \\ 'Mathematica Policy Research, Princeton, \\ New Jersey \\ ${ }^{2}$ Group Health Research Institute, Seattle, \\ Washington \\ ${ }^{3}$ Centers for Medicare and Medicaid \\ Services, Baltimore, Maryland
}

${ }^{4}$ American Board of Internal Medicine, Philadelphia, Pennsylvania

Conflicts of interest: authors report none.

\section{CORRESPONDING AUTHOR}

Deborah N. Peikes, PhD, MPA

Mathematica Policy Research Inc

PO Box 2393

Princeton, NJ 08543-2293

dpeikes@mathematica-mpr.com

\begin{abstract}
PURPOSE Despite growing calls for team-based care, the current staff composition of primary care practices is unknown. We describe staffing patterns for primary care practices in the Centers for Medicare and Medicaid Services (CMS) Comprehensive Primary Care (CPC) initiative.
\end{abstract}

METHODS We undertook a descriptive analysis of CPC initiative practices' baseline staffing using data from initial applications and a practice survey. CMS selected 502 primary care practices (from 987 applicants) in 7 regions based on their health information technology, number of patients covered by participating payers, and other factors; 496 practices were included in this analysis.

RESULTS Consistent with the national distribution, most of the CPC initiative practices included in this study were small: $44 \%$ reported 2 or fewer full-time equivalent (FTE) physicians; $27 \%$ reported more than 4 . Nearly all reported administrative staff (98\%) and medical assistants (89\%). Fifty-three percent reported having nurse practitioners or physician assistants; $47 \%$, licensed practical or vocational nurses; $36 \%$, registered nurses; and 24\%, care managers/coordinators-all of these positions are more common in larger practices. Other clinical staff were reported infrequently regardless of practice size. Compared with other CPC initiative practices, designated patient-centered medical homes were more likely to have care managers/coordinators but otherwise had similar staff types. Larger practices had fewer FTE staff per physician.

CONCLUSIONS At baseline, most CPC initiative practices used traditional staffing models and did not report having dedicated staff who may be integral to new primary care models, such as care coordinators, health educators, behavioral health specialists, and pharmacists. Without such staff and payment for their services, practices are unlikely to deliver comprehensive, coordinated, and accessible care to patients at a sustainable cost.

Ann Fam Med 2014;142-149. doi: 10.1370/afm.1626.

\section{INTRODUCTION}

$\mathrm{P}$ ublic and private health care payers nationwide are testing whether making primary care more patient centered, accessible, coordinated, and comprehensive will improve health care quality, cost, and patient and clinician experiences. ${ }^{1-3}$ Many are piloting versions of the patient-centered medical home $(\mathrm{PCMH})$ model as defined by the primary care physician societies. ${ }^{4}$

A cornerstone of these new care models is team-based care, in which staff work collaboratively with patients and their caregivers to achieve coordinated, high-quality care. ${ }^{5-12}$ Traditional staff, such as medical assistants, often take on expanded roles, and new staff types may be added. The team is expected to collaborate to deliver high-quality, comprehensive care efficiently; however, we know little about the current or optimal practice team composition.

Expanding staffing and shifting roles offers possible advantages. Expanded staffing could provide additional expertise and resources to support patient-centered, evidence-based primary care ${ }^{13}$ and underpins the chronic care model. ${ }^{14}$ Several successful care coordination interven- 
tions have leveraged interdisciplinary teams to support patient self-management and improve disease control. ${ }^{15-18}$ Team-based care might also increase clinicians' job satisfaction. ${ }^{19}$

Regarding costs, expanded teams may perform some functions more efficiently, but providing additional services to patients also requires more resources. ${ }^{11,20-25}$ Ideally, improved primary care will decrease total costs by reducing downstream use of other services.

Team-based care may also change primary care physicians' work. Midlevel clinicians and other staff who deliver the full range of care they are qualified to perform may provide some services more efficiently and effectively than physicians alone. Team-based care could help overcome primary care physician shortages and excessive panel sizes by shifting some tasks from physicians to other staff. ${ }^{26-28}$ Effective intrateam communication and problem solving could support continuous quality improvement. ${ }^{29}$

Although team-based care has potential benefits, it may cause communication and management challenges, difficulty in delineating responsibilities, and care fragmentation. Relational continuity, which is associated with better quality and lower costs, ${ }^{30,31}$ may be disrupted as more staff provide care.

Overall, little is known about the appropriate staffing composition for team-based primary care. Some studies indicate most small and medium-sized practices - the great majority of US practices ${ }^{32}$ - do not deliver team-based care. ${ }^{33}$ One explanation may be inadequate or inefficient staffing.

We describe the size and staffing composition of 496 technologically advanced practices committed to improving their primary care capabilities-those participating in the Centers for Medicare and Medicaid Services (CMS) Comprehensive Primary Care (CPC) initiative. In October 2012, Medicare and other payers began distributing enhanced payments to participating primary care practices in 7 selected regions, providing quarterly feedback on patient outcomes, and offering technical assistance to improve primary care functioning. ${ }^{34} \mathrm{We}$ examine staffing overall, by practice size, and by PCMH designation at the launch of the CPC initiative. Because these practices committed to practice transformation, we expect them to be more advanced in team-based care than most other practices. We further describe staffing gaps among these practices and discuss areas for improvement.

\section{METHODS}

\section{Participants and Setting}

CMS selected 7 regions for the CPC initiative, based largely on the percentage of patients covered by payers willing to participate in CPC initiative and the regions' previous participation in multistakeholder initiatives.

The selection ensured that practices would receive the enhanced payments needed to support practice transformation for a sizable proportion of their patients. The selected regions include 4 states (Arkansas, Colorado, New Jersey, and Oregon) and 3 portions of states (New York's Capital District-Hudson Valley region, the Cincinnati-Dayton region in Ohio and Kentucky, and Oklahoma's greater Tulsa region).

CMS invited primary care practice sites within the regions to apply for the $\mathrm{CPC}$ initiative. (Practice sites, hereafter called practices, are defined as groups of clinicians practicing in 1 location.) Practices were eligible if they (1) had mainly primary care clinicians (physicians [excluding pediatricians, obstetricians, and gynecologists], nurse practitioners, or physician assistants) ${ }_{i}(2)$ provided largely primary care services (evaluation and management visits, nursing home and home care, and welcome to Medicare and annual wellness visits); (3) were not federally qualified health centers or rural health clinics; $(4)$ served at least 120 Medicare beneficiaries attributed to the practice (ie, provided most primary care visits in the prior 2 years); and (5) were not participating in any other Medicare shared savings programs. CMS selected practices primarily on the basis of (1) having eligible primary care clinicians who, under the Medicare and Medicaid Electronic Health Record (EHR) Incentive Programs, attested to meaningfully using certified EHRs to improve patient care, ${ }^{35}$ and (2) receiving at least $40 \%$ of their revenue from participating payers. CMS also considered PCMH designation, past participation in practice transformation efforts, and geographic diversity. CMS selected 502 practices from 978 applicants. ${ }^{36,37}$ Five practices withdrew early, and we excluded one practice because it was led by a nurse practitioner only, and had no physicians, leaving 496 practices.

\section{Data Sources}

We used 4 data sources for practices' characteristics and staffing, collected before practices began CPC initiative transformation: (1) practices' summer 2012 applications to the CPC initiative ${ }_{i}(2)$ rosters of all Medicare and other patients seen by practices in the previous year; (3) an October 2012 CPC initiative practice survey that collected staffing information; and (4) the Area Resource File. The CPC initiative practice survey instructions asked the practice manager to complete it with input from other staff as needed.

Under the Common Rule and National Institute of Health's Exemption Number 5, this study is exempt from institutional review board review for research and demonstration projects on public benefits and service programs. $^{38,39}$ 


\section{Analysis}

We analyzed staff composition overall and by practice size measured by the number of full-time equivalent (FTE) physicians, and whether the practice reported being a recognized PCMH. (Ideally, we would have calculated staffing ratios per clinician-defined as physicians, nurse practitioners, and physician assistants-rather than per physician, however, we lacked data on which nurse practitioners and physician assistants operate and bill as clinicians.) Because we focused on describing the current staffing of these pioneering practices, we did not conduct statistical tests or report confidence intervals.

\section{RESULTS}

\section{Practice Size and Composition}

Like most US practices, most CPC initiative practices were small, with an average of 3.7 physicians. Eighty-five percent of the practices were in metropolitan areas. According to patient rosters, the CPC initiative practices served an average of 1,476 patients per FTE physician in the past year.

Not surprisingly, given the selection process, CPC initiative practices differed substantially from practices nationally. Comparison of national data with CPC initiative practices is, however, complicated by a difference in how practices are defined. If a practice has more than 1 location, the national sample includes all locations, whereas CPC treats each practice location as a unique practice. In addition, unlike the CPC initiative, the national sample excludes practices with 20 or more physicians, and practices were surveyed between 2007 and 2009. These distinctions, however, are unlikely to account for the sizeable differences observed between the CPC initiative practices and the national sample. Only $54.4 \%$ of the CPC initiative practices were physician-owned, compared with $89.5 \%$ of the small and medium-sized practices nationally, and the CPC initiative practices were nearly twice as likely to be multispecialty (Table 1). ${ }^{33}$

Of the eligible clinicians in the CPC initiative practices, $67.8 \%$ were meaningful EHR users, reflecting the selec- tion criteria, compared with about $18 \%$ of primary care physicians nationwide. ${ }^{40}$ Nearly $80 \%$ of the CPC initiative practices had at least 1 verified meaningful user.

\section{Nontraditional Staff Uncommon, Especially Among Smaller and Non-PCMH Practices}

More than $88 \%$ of practices reported having administrative staff and medical assistants (Table 2). The next most common staff were nurse practitioners and/or physician assistants. Fewer than one-half of the practices had licensed practical or vocational nurses, registered nurses, or care managers/coordinators. Seven percent had pharmacists, and $4 \%$ to $5 \%$ had social workers, community service coordinators, health educators, or nutritionists. Taken together, $16 \%$ of practices reported having any of these uncommon types of staff (not shown).
Table 1. CPC Initiative Practice Characteristics Compared With National Benchmarks

\begin{tabular}{|c|c|c|}
\hline Practice Characteristic & $\begin{array}{l}\text { CPC Initiative } \\
\text { Practices } \\
(n=496)\end{array}$ & $\begin{array}{c}\text { National } \\
\text { Benchmark }\end{array}$ \\
\hline $\begin{array}{l}\text { Primary care or multispecialty practice: multispe- } \\
\text { cialty, \% }\end{array}$ & 11.9 & 6.1 \\
\hline \multicolumn{3}{|l|}{ Ownership, \% } \\
\hline $\begin{array}{l}\text { Owned by hospital, hospital system, academic } \\
\text { institution, or HMO }\end{array}$ & 43.8 & 10.5 \\
\hline Owned by physicians & 54.4 & 89.5 \\
\hline Owned by government or other organization & 1.8 & NR \\
\hline Patient mix: African American patients, \% & 4.6 & 13.4 \\
\hline Patients per FTE physician in practice, average No. & $1,475.5$ & NR \\
\hline \multicolumn{3}{|l|}{$\begin{array}{l}\text { Distribution of number of patients per FTE physi- } \\
\text { cians in practice, \% }\end{array}$} \\
\hline$<500$ & 6.0 & NR \\
\hline $500-1,000$ & 22.6 & NR \\
\hline $1,000-1,499$ & 36.7 & NR \\
\hline $1,500-1,999$ & 16.5 & NR \\
\hline $2,000-2,499$ & 9.1 & NR \\
\hline$\geq 2,500$ & 9.0 & NR \\
\hline $\begin{array}{l}\text { Primary care physicians attesting as meaningful } \\
\text { users of electronic health records, } \%\end{array}$ & 67.8 & 17.8 \\
\hline \multicolumn{3}{|l|}{ Practice location, \% } \\
\hline Located in metropolitan area & 84.7 & NR \\
\hline Located in nonmetropolitan area & 15.3 & NR \\
\hline
\end{tabular}

$\mathrm{CPC}=$ Comprehensive Primary Care; FTE = full-time equivalent; $\mathrm{HMO}=$ health maintenance organization; $\mathrm{NR}=$ not reported.

Source: For CPC initiative practices, data for the percentage of African American patients per practice are from the Medicare Enrollment Data base; data on the number of patients per FTE physician per practice are from the patient roster; the other data are from the CPC initiative practice application. Metropolitan and nonmetropolitan areas are based on the US Census urban/rural continuum code as reported in the 2009 Area Resource File. National benchmarks for electronic health record meaningful use estimates are based on meaningful-use attestation data provided by CMS and reported by Wright et al. $^{40}$ All other national benchmarks come from a survey fielded between July 2007 and March 2009 for the National Study of Small and Medium-Sized Physician Practices, a nationally representative, random sample of 1,325 practices with fewer than 20 physicians drawn from the IMS Healthcare Organization Services database. The survey had an overall response rate of $63.2 \%$. Results were restricted to practices that had at least $33 \%$ primary care physicians. Unlike the CPC initiative sample, a practice was not restricted to clinicians who were practicing in the same physical location. 
Table 2. Percentage of CPC Initiative Practices With Different Staff Types, by Practice Size

\begin{tabular}{|c|c|c|c|c|c|c|}
\hline Staff Type & $\begin{array}{c}\leq 2 \text { FTE } \\
\text { Physicians }\end{array}$ & $\begin{array}{l}>2-4 \text { FTE } \\
\text { Physicians }\end{array}$ & $\begin{array}{l}>4-7 \text { FTE } \\
\text { Physicians }\end{array}$ & $\begin{array}{l}\text { >7-13 FTE } \\
\text { Physicians }\end{array}$ & $\begin{array}{c}>13 \text { FTE } \\
\text { Physicians }\end{array}$ & All Practices \\
\hline Practice sample, No. (\%) & $216(43.5)$ & $148(29.8)$ & $92(18.5)$ & $31(6.3)$ & $9(1.8)$ & $496(100.0)$ \\
\hline \multicolumn{7}{|l|}{ Practices with each staff type, \% } \\
\hline Administrative staffa & 96.3 & 100.0 & 100.0 & 100.0 & 100.0 & 98.4 \\
\hline Medical assistants & 79.2 & 95.9 & 96.7 & 93.5 & 88.9 & 88.5 \\
\hline NPs, PAs & 52.8 & 48.6 & 48.9 & 74.2 & 100.0 & 53.0 \\
\hline LPNs, LVNs & 40.3 & 42.6 & 56.5 & 67.7 & 88.9 & 46.6 \\
\hline RNs & 29.2 & 29.1 & 43.5 & 77.4 & 88.9 & 35.9 \\
\hline Care managers/coordinators & 17.6 & 23.0 & 31.5 & 48.4 & 33.3 & 24.0 \\
\hline Pharmacists & 1.4 & 6.8 & 12.0 & 25.8 & 33.3 & 7.1 \\
\hline Social workers & 0.9 & 4.1 & 8.7 & 22.6 & 22.2 & 5.0 \\
\hline Community service coordinators & 4.2 & 3.4 & 4.3 & 9.7 & 11.1 & 4.4 \\
\hline Health educators & 2.3 & 3.4 & 6.5 & 6.5 & 22.2 & 4.0 \\
\hline Nutritionists & 1.9 & 4.1 & 5.4 & 6.5 & 33.3 & 4.0 \\
\hline
\end{tabular}

Although the likelihood that a practice had medical assistants and administrative staff did not vary by practice size, larger practices were more likely to have nurses and other staff. For example, the proportion of practices with a licensed practical or vocational nurse increased from $42.6 \%$ for practices with 2.01 to 4 FTE physicians to $88.9 \%$ for practices with more than 13 FTE physicians. Similarly, use of care managers/coordinators increased with practice size. Although only $17.6 \%$ of the smallest practices reported having care managers/coordinators, the percentages ranged from $31.5 \%$ to $48.4 \%$ for practices with more than 4 FTE physicians. Use of 1 or more of 5 staff types (pharmacists, social workers, community service coordinators, health educators, and nutritionists) also increased with practice size $;$ 8\% of practices with 2 or fewer FTE physicians and more than $26 \%$ of practices with more than 4 FTE physicians employed any of these types of staff (data not shown).

PCMHs are encouraged to use team-based care and provide more coordinated and comprehensive care than traditional primary care practices. We therefore examined staffing in CPC initiative practices by $\mathrm{PCMH}$ recognition status (Table 3). Staffing was remarkably similar between the 2 types of practices, with 2 exceptions. Consistent with the PCMH emphasis on care coordination, $\mathrm{PCMH}$ practices are more likely to report dedicated care managers/ coordinators. Still, only $41.7 \%$ include this staff type (Table 3). PCMH practices were also more likely to use any of the last 5 staff types shown in Table 3, but use was still uncommon; they were employed at $23 \%$ of $\mathrm{PCMH}$ practices, compared with $10 \%$ of other practices (data not shown).

\section{Larger Practices May Have Economies of Scale} In addition to examining the percentage of practices with particular types of staff (Tables 1 through 3 ),
Table 3. Percentage of CPC Initiative Practices With Staff Types, by PCMH Status

\begin{tabular}{lcc}
\hline & $\begin{array}{c}\text { PCMH Practices } \\
\text { (n = 204) }\end{array}$ & $\begin{array}{c}\text { Other Practices } \\
\text { (n = 292) }\end{array}$ \\
Staff Type & 100.0 & 100.0 \\
\hline Physicians & 98.5 & 98.3 \\
Administrative staff ${ }^{b}$ & 93.1 & 85.3 \\
Medical assistants & 53.4 & 52.7 \\
NPs, PAs & 40.2 & 51.0 \\
LPNs, LVNs & 41.2 & 32.2 \\
RNs & 41.7 & 11.6 \\
Care managers/coordinators & 9.3 & 5.5 \\
Pharmacists & 7.4 & 3.4 \\
Social workers & 5.9 & 3.4 \\
Community service coordinators & 2.9 & 2.7 \\
Health educators & 5.9 & \\
Nutritionists & & \\
\hline CPC = Comprehensive Primary Care; FTE = full-time equivalent; LPN = licensed practical \\
nurse; LVN = licensed vocational nurse; NP = nurse practitioner; PA = physician assistant; \\
PCMH = patient-centered medical home; RN = registered nurse. \\
Source: The CPC initiative practice survey, fielded October through December 2012. \\
a Practices were classified as a PCMH if they reported they had received PCMH recogni- \\
tion, accreditation, or certification from 1 or more of the following: The Accreditation \\
Association of Ambulatory Healthcare, The Joint Commission, the National Committee for \\
Quality Assurance, the Utilization Review Accreditation Association, or a state- or insur- \\
ance plan-based recognition program. \\
${ }^{b}$ Administrative staff include those managing reception, medical records, appointments, \\
finance, etc. & & \\
\hline
\end{tabular}


Table 4. Mean Number of FTE Staff per FTE Physician-Among CPC Initiative Practices With Staff Type-by Practice Size

\begin{tabular}{|c|c|c|c|c|c|}
\hline Staff Type & $\begin{array}{c}\leq 2 \text { FTE } \\
\text { Physicians } \\
(n=216)\end{array}$ & $\begin{array}{c}>2-4 \text { FTE } \\
\text { Physicians } \\
(n=148)\end{array}$ & $\begin{array}{c}>4-7 \text { FTE } \\
\text { Physicians } \\
(n=92)\end{array}$ & $\begin{array}{c}\text { >7 FTE } \\
\text { Physicians } \\
(n=40)\end{array}$ & $\begin{array}{c}\text { All } \\
\text { Practices } \\
(n=496)\end{array}$ \\
\hline $\begin{array}{l}\text { Administrative } \\
\text { staff a }^{\text {a }}\end{array}$ & 2.42 & 1.76 & 1.70 & 1.98 & 2.05 \\
\hline Medical assistants & 1.76 & 1.31 & 1.23 & 1.11 & 1.45 \\
\hline NPS, PAs & 0.97 & 0.49 & 0.38 & 0.20 & 0.65 \\
\hline LPNs, LVNs & 1.38 & 0.78 & 0.66 & 0.53 & 0.95 \\
\hline RNs & 1.04 & 0.54 & 0.38 & 0.31 & 0.64 \\
\hline $\begin{array}{l}\text { Care managers/ } \\
\text { coordinators }\end{array}$ & 0.77 & 0.46 & 0.24 & 0.23 & 0.47 \\
\hline Pharmacists & 0.75 & 0.42 & 0.15 & 0.29 & 0.32 \\
\hline Social workers & 0.75 & 0.22 & 0.13 & 0.12 & 0.20 \\
\hline $\begin{array}{l}\text { Community ser- } \\
\text { vice coordinators }\end{array}$ & 0.86 & 0.26 & 0.17 & 0.20 & 0.48 \\
\hline Health educators & 1.00 & 0.37 & 0.19 & 0.10 & 0.42 \\
\hline Nutritionists & 0.58 & 0.38 & 0.08 & 0.07 & 0.27 \\
\hline \multicolumn{6}{|c|}{$\begin{array}{l}\mathrm{CPC}=\text { Comprehensive Primary Care; } \mathrm{FTE}=\text { full-time equivalent; } \mathrm{LPN}=\text { licensed practical nurse; } \mathrm{LVN}=\text { licensed } \\
\text { vocational nurse; } \mathrm{NP}=\text { nurse practitioner; } \mathrm{PA}=\text { physician assistant; } \mathrm{RN}=\text { registered nurse. }\end{array}$} \\
\hline \multicolumn{6}{|c|}{ Source: The CPC practice survey, fielded October through December 2012.} \\
\hline \multicolumn{6}{|c|}{ Note: Practice size is defined by the number of FTE physicians. } \\
\hline
\end{tabular}

fewer FTEs of that staff per FTE physician. This pattern holds across all staff types. For example, the average number of FTE nurse practitioners or physician assistants per FTE physician ranges from 0.97 in the smallest practices to 0.20 in the largest. FTE care managers/ coordinators per FTE physician range from 0.77 in small practices to 0.23 in the largest.

Among all CPC initiative practices, the ratio of all FTE staff to FTE physician is 4.50 (2.49 are nonadministrative staff, and 2.01 are administrative staff). The Medical Group Management Association reported that nationwide, internal medicine practices owned by a hospital or integrated delivery system reported 2.68 FTE staff per FTE physician

we analyzed the number of each staff type per FTE physician-among practices reporting having each type of staff. The number of FTE staff per FTE physician among all practices that reported having a given type of staff varied from 2.05 administrative staff and 1.45 medical assistants to 0.20 social workers (Table 4). Among practices that reported having a particular type of staff, larger practices tended to report having in 2009. ${ }^{41}$ This benchmark is different from that of the CPC initiative sample, as just less than one-half of CPC initiative practices are owned by a larger organization. The staffing ratio among CPC initiative practices falls from a ratio of 5.32 among the smallest practices to 3.35 for the largest (Table 5). There is little difference between practices with and without PCMH designation.

Table 5. Staffing Ratios, Overall, and by Practice Size and PCMH Status

\begin{tabular}{|c|c|c|c|c|c|c|c|c|}
\hline \multirow[b]{2}{*}{ Staff Type } & \multicolumn{5}{|c|}{ Practice Size } & \multicolumn{2}{|c|}{ PCMH Status } & \multirow[b]{2}{*}{$\begin{array}{c}\text { All } \\
\text { Practices }\end{array}$} \\
\hline & $\begin{array}{c}\leq 2 \text { FTE } \\
\text { Physicians }\end{array}$ & $\begin{array}{l}\text { >2-4 FTE } \\
\text { Physicians }\end{array}$ & $\begin{array}{l}\text { >4-7 FTE } \\
\text { Physicians }\end{array}$ & $\begin{array}{l}\text { >7-13 FTE } \\
\text { Physicians }\end{array}$ & $\begin{array}{c}>13 \text { FTE } \\
\text { Physicians }\end{array}$ & $\begin{array}{c}\text { PCMH } \\
\text { Practices }\end{array}$ & $\begin{array}{c}\text { Other } \\
\text { Practices }\end{array}$ & \\
\hline \multicolumn{9}{|l|}{$\begin{array}{l}\text { Ratio of FTE nonphysician } \\
\text { staff to FTE physician }\end{array}$} \\
\hline All nonphysician staff a & 5.32 & 3.92 & 3.73 & 4.23 & 3.35 & 4.40 & 4.57 & 4.50 \\
\hline All nonadministrative staff & 2.99 & 2.16 & 2.04 & 2.21 & 1.52 & 2.50 & 2.48 & 2.49 \\
\hline Administrative staff & 2.33 & 1.76 & 1.70 & 2.02 & 1.83 & 1.90 & 2.09 & 2.01 \\
\hline \multicolumn{9}{|l|}{ FTE physicians } \\
\hline $\begin{array}{l}\text { Average number of FTE } \\
\text { physicians }\end{array}$ & 1.4 & 3.4 & 5.5 & 9.4 & 27.7 & 4.3 & 3.4 & 3.7 \\
\hline $\begin{array}{l}\text { Median number of FTE } \\
\text { physicians }\end{array}$ & 1.0 & 3.0 & 5.0 & 9.0 & 15.6 & 3.0 & 2.9 & 3.0 \\
\hline \multicolumn{9}{|c|}{$\begin{array}{l}\mathrm{CPC}=\text { Comprehensive Primary Care; } \mathrm{FTE}=\text { full-time equivalent; } \mathrm{LPN}=\text { licensed practical nurse; } \mathrm{LVN}=\text { licensed vocational nurse; } \mathrm{NP}=\text { nurse practitioner; } \mathrm{PA}=\text { physician } \\
\text { assistant; } \mathrm{PCMH}=\text { patient-centered medical home; } \mathrm{RN}=\text { registered nurse. }\end{array}$} \\
\hline \multicolumn{9}{|c|}{ Source: The CPC initiative practice survey, fielded October through December 2012.} \\
\hline \multicolumn{9}{|c|}{$\begin{array}{l}\text { Note: Practice size is defined by the number of FTE physicians. Practice status is based on whether a practice reported it had received PCMH recognition, accreditation, } \\
\text { or certification from } 1 \text { or more of the following: The Accreditation Association of Ambulatory Healthcare, The Joint Commission, the National Committee for Quality } \\
\text { Assurance, the Utilization Review Accreditation Association, or a state- or insurance plan-based recognition program. }\end{array}$} \\
\hline
\end{tabular}




\section{DISCUSSION}

Most CPC initiative practices used traditional staffing models before the initiative began. Most did not report having dedicated staff who the literature speculates may be integral to providing comprehensive team-based primary care-staff who provide health education, care coordination, behavioral health care, nutrition counseling, and medication adherence and reconciliation. ${ }^{12}$ About one-half of practices reported having nurse practitioners or physician assistants, $24 \%$ reported having care managers/coordinators, and $7 \%$ percent or fewer reported having pharmacists, social workers, community service coordinators, health educators, or nutritionists.

This relatively restricted staff composition is not surprising. A largely fee-for-service payment environment-where practices are rewarded only for services provided by certain team members rather than outcomes-does not provide incentives to expand the care team to deliver comprehensive, coordinated care. The relatively high prevalence of nurse practitioners and physician assistants compared with other staff may reflect their ability to directly deliver revenue-generating services under the current payment system.

Our results raise questions about the ideal size of a practice to provide cost-effective care, suggesting that bigger practices may enjoy economies of scale. These practices may require fewer staff of a given type per FTE physician, because physicians can share the staff. We cannot confirm this possibility, however, because we cannot ascertain whether larger practices (1) distribute tasks differently, (2) provide different types of care, (3) have different abilities to hire part-time nonphysician staff, and (4) may not report staff who are shared with a larger medical group or supplied by a parent organization, such as a hospital.

More work is needed to identify the practice size, team compositions, and staffing ratios that support better patient outcomes and cost efficiencies. ${ }^{12}$ For example, it is possible that challenges of coordination across a larger staff could inadvertently reduce care quality. It is also possible that patients might receive less continuity with their personal clinician if in larger practices, they are seen by other clinicians in the practice, or in smaller practices, they go to other practices when they cannot obtain a timely appointment at the practice. In addition, continuity with the patient's clinician might be lost when more primary care team members provide care.

Currently, as Rittenhouse and Shortell observe, the "evidence is insufficient to inform current policy debates about the ideal staffing of a primary care practice." ${ }^{22(\mathrm{p} 2038)}$ Although a recent article adds to the debate by proposing staffing for $\mathrm{PCMHs},{ }^{41}$ it does so based on the experience of a small number of practices and professional judgment, rather than on data linking specific staffing to better outcomes. Furthermore, the ideal composition may vary by practice size, patient mix, and the area's medical and social service providers. As the CPC initiative unfolds, we will examine any changes in staff size and composition and whether these changes are associated with cost, quality, and patient and clinician experiences. Such evidence could help guide staffing and payment decisions of policy makers and practice leaders.

If the evidence suggests that certain staffing patterns improve outcomes, payers may need to identify different payment approaches before practices change staffing levels and configurations. ${ }^{43}$ If payers shift toward reimbursing for value rather than volume, practices will gain incentives to create the most efficacious, efficient teams rather than the compositions that maximize billable services.

Even with financial incentives that reward primary care practices for providing comprehensive care and improved outcomes, change will be difficult. Many physicians will require support and training to hire, manage, and work effectively in teams that change the roles of existing staff and add new staff categories. ${ }^{44}$ Guidance could be provided during medical school and residency and through ongoing quality improvement initiatives for practicing physicians. Community colleges and vocational programs could provide training for some staff. Attitudinal shifts may also be needed. ${ }^{45}$

If most US primary care practices remain small, achieving the economies of scale needed to support an expanded staff with relatively small patient panels would require creative solutions. Possible approaches include market forces leading to consolidation of practices, small practices sharing staff with neighboring practices or as part of an Accountable Care Organization, and communities (eg, Vermont's Blueprint for Health) or insurers providing external staff.

This study has several limitations. First, although the sample is large and geographically diverse, it was not designed to be nationally representative of primary care practices ${ }_{i}$ hence, it cannot be used to draw inferences about practices nationwide. The sample is restricted to 7 specially selected regions with payers willing to devote resources to practice reform and, within those regions, to technologically advanced practices that applied to and were selected for the CPC initiative. Although these practices may be more innovative than are practices nationwide, we expect that they share similar, mostly traditional, staffing patterns with practices nationwide.

Second, although we know the types of staff that practices report having, we do not know their roles, 
which may differ. For example, the functions performed by a medical assistant in one practice may be performed by a nurse in another. Similarly, the care coordination function is often spread among many staff other than a care coordinator.

Third, although many nurse practitioners and physician assistants operate as clinicians and would ideally be included alongside physicians in staffing ratios, we did not have information on which nurse practitioners and physician assistants bill for visits. Our future work will collect information on staff roles.

Fourth, for practices with multiple office sites, each site is treated as a separate practice, which may have led some practices not to report staff shared across a larger medical group or host organization. Even so, however, this omission would raise the question of how much the omitted staff are truly part of the practice team.

Finally, the measure of PCMH status may imprecisely capture actual PCMH functionality. Some practices may not have applied for recognition, accreditation, or certification because payers in their region were not reimbursing $\mathrm{PCMH}$ s more ${ }_{i}$ also, $\mathrm{PCMHs}$ likely vary in their functionality.

Despite these limitations, our results contribute to the literature by describing staffing patterns among 496 technologically advanced primary care practices and illustrate the gap between where they are and the expectations many policy makers have for them. Future research is needed to understand what functions are optimally performed by which staff and what changes in staff size and composition improve outcomes for different types of practices and patients. We plan to examine how staffing changes made by these CPC initiative practices alter patient outcomes; we expect that without such staff-and payment for their services— practices are unlikely to deliver comprehensive, coordinated, and accessible care to patients at a sustainable cost.

To read or post commentaries in response to this article, see it online at http://www.annfammed.org/content/12/2/142.

Key words: primary care; staffing; patient-centered medical home; team-based care

Submitted June 14, 2013; submitted, revised, December 16, 2013; accepted January 6, 2014.

Funding support: This study was funded by the Centers for Medicare and Medicaid Services, contract No. HHSM-500-2010-00026I/ HHSM-500-T0006.

Disclaimer: The statements contained herein are those of the authors and do not necessarily reflect the views or policies of the Centers for Medicare and Medicaid Services.

Acknowledgments: The authors thank Eugene Rich, MD (Mathematica Policy Research), Michael Parchman, MD, MPH (Group Health Research
Institute), and William Shrank, MD, MSHS (CVS Caremark), for their comments and suggestions on earlier versions of the manuscript. We also thank Mathematica Policy Research employees Ae Sengmavong, MA, Thomas Decker, MS, Jeffrey Holt, BA, and Xiaofan Sun, MPA, for database construction and programming; and John Kennedy, MA, and Cindy George, EdM, for editing.

Author contributions: Dr Peikes and Ms Dale had full access to all of the data in the study and take full responsibility for the integrity of the data and the accuracy of the data analysis. All authors contributed to the survey content, analysis, and reporting.

\section{References}

1. Bodenheimer T, Pham HH. Primary care: current problems and proposed solutions. Health Aff (Millwood). 2010;29(5):799-805.

2. Berenson RA, Rich ECUS. US approaches to physician payment: the deconstruction of primary care. J Gen Intern Med. 2010;25(6):613-618.

3. Meyers DS, Clancy CM. Primary care: too important to fail. Ann Intern Med. 2009;150(4):272-273.

4. American Academy of Family Physicians, American Academy of Pediatrics, American College of Physicians, American Osteopathic Association. Joint Principles of the Patient-Centered Medical Home. http://www.aafp.org/dam/AAFP/documents/practice_management/ pcmh/initiatives/PCMHJoint.pdf. 2007. Accessed Jun 10, 2013.

5. Pew Health Professions Commission. Critical Challenges: Revitalizing the Health Professions for the Twenty-First Century. San Francisco, CA: UCSF Center for the Health Professions; 1995.

6. Institute of Medicine. Crossing the Quality Chasm: A New Health System for the 21st Century. Washington, DC: National Academy Press; 2001.

7. Gawande A. Cowboys and pit crews. Commencement Address: Harvard Medical School; May 2011; Cambridge, MA.

8. Patient Centered Primary Care Implementation Work Group, US Department of Veterans Affairs. Patient-aligned care team (PACT). http://www.va.gov/PrimaryCare/docs/pcmh_ConceptPaper.doc. Accessed Mar 14, 2013.

9. TRICARE. Military medical health system patient centered medical home guide. http://www.tricare.mil/tma/ocmo/download/MHSPCMHGuide.pdf. 2011. Accessed Mar 14, 2013.

10. National Committee for Quality Assurance. NCQA's Patient-centered Medical Home (PCMH) 2011 Standards. Washington, DC: NCQA; 2011.

11. Naylor M, Coburn K, Kurtzman E, et al. Inter-professional teambased primary care for chronically ill adults: state of the science. Manuscript commissioned for: ABIM Foundation and American Academy of Nursing Meeting on Advancing Team-Based Care for the Chronically III; March 24-25, 2010; Philadelphia, PA. Cited by: Mitchell P, Wynia M, Golden R, et al. Core Principles $\&$ Values of Effective Team-Based Care. Washington, DC: Institute of Medicine; October 2012.

12. Doherty RB, Crowley RA; Health and Public Policy Committee of the American College of Physicians. Principles supporting dynamic clinical care teams: an American College of Physicians position paper. Ann Intern Med. 2013;159(9):620-626. http://annals.org/ article. aspx?articleid $=1737233$.

13. Starfield B. Primary Care: Balancing Health Needs, Services and Technology. New York, NY: Oxford University Press; 1998.

14. Wagner EH, Austin BT, Davis C, Hindmarsh M, Schaefer J, Bonomi A. Improving chronic illness care: translating evidence into action. Health Aff (Millwood). 2001;20(6):64-78.

15. Shojania KG, Ranji SR, McDonald KM, et al. Effects of quality improvement strategies for type 2 diabetes on glycemic control: a meta-regression analysis. JAMA. 2006;296(4):427-440. 
16. Walsh JM, McDonald KM, Shojania KG, et al. Quality improvement strategies for hypertension management: a systematic review. Med Care. 2006;44(7):646-657.

17. Gilbody S, Bower P, Fletcher J, Richards D, Sutton AJ. Collaborative care for depression: a cumulative meta-analysis and review of longer-term outcomes. Arch Intern Med. 2006;166(21):2314-2321.

18. Wagner $\mathrm{EH}$. The role of patient care teams in chronic disease management. BMJ. 2000;320(7234):569-572.

19. Sinsky CA, Willard-Grace R, Schutzbank AM, Sinsky TA, Margolius $D$, Bodenheimer $T$. In search of joy in practice: a report of 23 highfunctioning primary care practices. Ann Fam Med. 2013;11(3):272-278.

20. Flood AB, Fremont AM, Jin K, Bott DM, Ding J, Parker RC Jr. How do HMOs achieve savings? The effectiveness of one organization's strategies. Health Serv Res. 1998;33(1):79-99.

21. Grzybicki DM, Sullivan PJ, Oppy JM, Bethke AM, Raab SS. The economic benefit for family/general medicine practices employing physician assistants. Am J Manag Care. 2002;8(7):613-620.

22. Hooker RS. A cost analysis of physician assistants in primary care. JAAPA. 2002;15(11):39-42, 45, 48 passim.

23. Venning P, Durie A, Roland M, Roberts C, Leese B. Randomised controlled trial comparing cost effectiveness of general practitioners and nurse practitioners in primary care. BMJ. 2000;320(7241):1048-1053.

24. Famadas JC, Frick KD, Haydar ZR, Nicewander D, Ballard D, Boult C. The effects of interdisciplinary outpatient geriatrics on the use, costs and quality of health services in the fee-for-service environment. Aging Clin Exp Res. 2008;20(6):556-561.

25. Boult C, Green AF, Boult LB, Pacala JT, Snyder C, Leff B. Successful models of comprehensive care for older adults with chronic conditions: evidence for the Institute of Medicine's "retooling for an aging America" report. J Am Geriatr Soc. 2009;57(12):2328-2337.

26. Yarnall KSH, Østbye T, Krause KM, Pollak KI, Gradison M, Michener JL. Family physicians as team leaders: "time" to share the care. Prev Chronic Dis. 2009;6(2):A59. http://www.cdc.gov/pcd/issues/2009/ apr/08_0023.htm. Accessed Mar 25, 2013.

27. Altschuler J, Margolius D, Bodenheimer T, Grumbach K. Estimating a reasonable patient panel size for primary care physicians with team-based task delegation. Ann Fam Med. 2012;10(5):396-400.

28. Bodenheimer TS, Smith MD. Primary care: proposed solutions to the physician shortage without training more physicians. Health Aff (Millwood). 2013;32(11):1881-1886.

29. Taylor EF, Peikes D, Genevro J, Meyers D. Creating Capacity for Improvement in Primary Care: The Case for Developing a Quality Improvement Infrastructure. Rockville, MD: Agency for Healthcare Research and Quality; 2013.

30. Haggerty JL, Reid RJ, Freeman GK, Starfield BH, Adair CE, McKendry R. Continuity of care: a multidisciplinary review. BMJ. 2003; 327(7425):1219-1221.

31. Saultz JW, Lochner J. Interpersonal continuity of care and care outcomes: a critical review. Ann Fam Med. 2005;3(2):159-166.
32. Hing ES, Burt CW. Office-based medical practices: methods and estimates from the national ambulatory medical care survey. Adv Data. 2007;12(383):1-15.

33. Rittenhouse DR, Casalino LP, Shortell SM, et al. Small and mediumsize physician practices use few patient-centered medical home processes. Health Aff (Millwood). 2011;30(8):1575-1584.

34. Centers for Medicare and Medicaid Services (CMS). Comprehensive primary care intiative. http://innovation.cms.gov/initiatives/Comprehensive-Primary-Care-Initiative/index.html. Accessed Mar 21, 2013.

35. Centers for Medicare and Medicaid Services (CMS). Meaningful use. http://www.cms.gov/Regulations-and-Guidance/Legislation/EHR IncentivePrograms/Meaningful_Use.html. Accessed May 22, 2013.

36. Centers for Medicare and Medicaid Services (CMS). Practice solicitation. http://innovation.cms.gov/Files/x/CPC_PracticeSolicitation.pdf. Accessed Mar 21, 2013.

37. Centers for Medicare and Medicaid Services (CMS). Payer solicitation. http://innovation.cms.gov/Files/x/Comprehensive-Primary-CareInitiative-Solicitation.pdf. Accessed Mar 21, 2013.

38. Office for Protection from Research Risks. OPRR guidance on 45 CFR 46.101(b)(5): exemption for research and demonstration projects on public benefit and service programs. http://www.hhs.gov/ ohrp/policy/exmpt-pb.html. Accessed Mar 21, 2013.

39. National Institutes of Health, Office of Extramural Research. Exemption 5. Glossary of terms for human subjects protection and inclusion issues. http://grants.nih.gov/grants/peer/tree_glossary.pdf. 2001. Accessed Mar 21, 2013.

40. Wright A, Henkin S, Feblowitz J, McCoy AB, Bates DW, Sittig DF. Early results of the meaningful use program for electronic health records. N Engl J Med. 2013;368(8):779-780.

41. Medical Group Management Association. Cost Survey for Single Specialty Practices: 2010 Report Based on 2009 Data. Englewood, CO: Medical Group Management Association. http://www.mgma. com/store/Surveys-and-Benchmarking/Cost-Survey-for-SingleSpecialty-Practices-2010-Report-Based-on-2009-Data-Print-Edition/. Published 2010. Accessed June 21, 2011. Cited by: Patel MS, Arron MJ, Sinsky TA, et al. Estimating the staffing infrastructure for a patient-centered medical home. Am J Manag Care. 2013;19(6):509-516.

42. Rittenhouse DR, Shortell SM. The patient-centered medical home: will it stand the test of health reform? JAMA. 2009;301(19):2038-2040.

43. Grumbach K, Bodenheimer T. Can health care teams improve primary care practice? JAMA. 2004;291(10):1246-1251.

44. Taplin SH, Foster MK, Shortell SM. Organizational leadership for building effective health care teams. Ann Fam Med. 2013;11(3):279-281.

45. Nutting PA, Crabtree BF, McDaniel RR. Small primary care practices face four hurdles-including a physician-centric mind-set-in becoming medical homes. Health Aff (Millwood). 2012;31(11):2417-2422. 